\title{
On Systems of Systems Engineering: Online Distance Education Systems Key Challenges
}

\author{
By Arwa A. Al Shamsi
}

The British University in Dubai

Abstract- Technology development have affected educational delivery around the world. The utilization and implementation of online learning is rising at a staggering manner. Online Distance learning has become an urgent need recently. The use of distance learning has appeared in the past ten years, the learning has been extended by the technology from classrooms in the schools into online learning. Online Learning adopted in various universities, educational institutions and schools worldwide. Recently, with the emergency situations due to the epidemic of COVID -19, and according to the recommendations by World Health Organization for social distance, most of the educational institutions worldwide tend to utilize the online learning instead of traditional learning. Although the online learning has been implemented years ago, still it faces challenges. The author of this research paper aim to explore the key challenges that reported while implementing Online Distance Education System as Systems of Systems. The author then outlines research agenda that identifies 11 research themes that can be considered as a solution for the current Online Distance Education System implementations challenges.

Keywords: online; learning; education; SoS; SoSE; challenges.

GJCST-H Classification: K.3.1

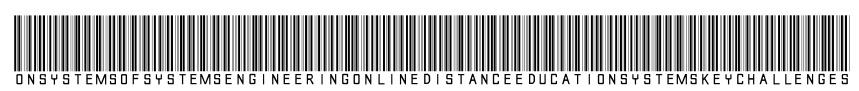

Strictly as per the compliance and regulations of:

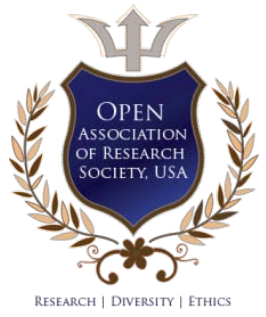

(C) 2020. Arwa A. Al Shamsi. This is a research/review paper, distributed under the terms of the Creative Commons AttributionNoncommercial 3.0 Unported License http://creativecommons.org/licenses/by-nc/3.0/), permitting all non-commercial use, distribution, and reproduction in any medium, provided the original work is properly cited. 


\title{
On Systems of Systems Engineering: Online Distance Education Systems Key Challenges
}

\author{
Arwa A. Al Shamsi
}

Abstract- Technology development have affected educational delivery around the world. The utilization and implementation of online learning is rising at a staggering manner. Online Distance learning has become an urgent need recently. The use of distance learning has appeared in the past ten years, the learning has been extended by the technology from classrooms in the schools into online learning. Online Learning adopted in various universities, educational institutions and schools worldwide. Recently, with the emergency situations due to the epidemic of COVID -19, and according to the recommendations by World Health Organization for social distance, most of the educational institutions worldwide tend to utilize the online learning instead of traditional learning. Although the online learning has been implemented years ago, still it faces challenges. The author of this research paper aim to explore the key challenges that reported while implementing Online Distance Education System as Systems of Systems. The author then outlines research agenda that identifies 11 research themes that can be considered as a solution for the current Online Distance Education System implementations challenges.

Keywords: online; learning; education; SoS; SoSE; challenges.

\section{INTRODUCTION}

$\| S$ ystem of Systems"(SoS) is an emerging topic that has been in use in recent years. SoS involve system consisting of several systems that are operated independently. SoS offer a way to reach the required set of capabilities which make them very important. SoS recently have been found in different areas, such as healthcare, defense, transport, education, energy and logistics. The developments in the field of science and technology in the 21st century have broadened the educational system's duties and responsibilities; new opportunities have also been brought [1]. Online Distance Education System which involve the Online Distance learning has been emerged with great benefits, it is considered as effective method for learning, it allows for class education to be offered to anyone anywhere all around the world. Moreover, Online Distance Learning Considered as cost effective [2]. Online learning is very attractive to a vast number of students, because it provides versatility of attendance, ease of access and comfort [3]. Online Distance Learning offered great solution in some urgent accidents and situations. Due to the recent urgent situation of

Author: Faculty of Engineering and IT, The British University in Dubai, Dubai, UAE.e-mail:20180935@student.buid.ac.ae
Corona Virus Emerging situation, Online Distance Learning considered as effective approach for Education while performing the social distancing and avoid gathering. However, the current implementations of Online Distance Education SoS have number of challenges that have been encountered. In this research paper, Author firstwill introduce the concept of SoS and SoSE. Second, author will present the types of SoS. Third, Education System as Systems of Systems SoS will be introduced. Forth, Online Distance Education System as System of Systems SoS will be introduced. Fifth, Online Distance Education System key challenges will be identified. Finally, author will propose a structure for the research agenda for the Future of Online Distance Education that can be considered as a solution for the current Online Distance Education implementations challenges.

\section{Literature Review}

\section{a) Systems of Systems SOS}

Systems of Systems shortly known as SoS. SoS concept has been addressed by large numbers of researches and identified in various ways. The key feature of SoS is that it consists of number of systems that function independently [4]. SoS concept become very common. It has been explored and addressed in different conferences, books, reports and researches [5]. One definition of SoS concept is as it is set of systems that are resulted from the integration of independent systems into bigger system that offer unique abilities[6]. Another definition of SoS concept as it is a composition of systems that are operated independently and managed independently [7]. SoS described by [8] as it has the following characteristics: systems operated, managed and evolved independently from their constituent systems, geographical distribution, and emergent behaviors. Although SoS definition has been addressed by number of researches, there is no exact definition of SoS concept [5]. However, it has been noticed that almost all the definitions of SoS agreed on the following characteristics of SoS i.e. complexity, variability, systems distributed geographically, independent subsystems, evolution, heterogeneity [5].

b) Systems of Systems Engineering SOSE

Systems of Systems Engineering shortly known as SoSE. SoSE is field that recently emerged in order to 
deal with problems that SoS posed. Although SoSE concept has been identified in number of research papers, there is no definition of SoSE that is accepted widely[9]. Below are some definitions of SoSE that are defined in research papers. SoSEinvolve utilizing the existing assets and take the value from them and then design new better assets that can be re-purposed[10] SoSE described by [8] asit involves constituent systems to be combined in order to fulfil the requirements that are frequently changing. SoSE identified by [11] as it involves plan, analyze, arrange and merge the abilities of constituent systems into SoS ability that is larger than the combination of the abilities of the constituent systems. Literature studied and explored SoSE concepts agreed on the following elements that are related to SoSE concept [9]. The most common and related elements to SoSE concept are systems independently operated and managed, distributed geographically, Interoperability, Complementarity, and Holism [9].

\section{c) Types of System of Systems SOS}

SoS classified into 4 types i.e. (a) Directed, (b)Acknowledged, (c) Collaborative, and (d) Virtual [8].

Directed SoS: consists of constituent systems that are independent and geographically distributed. The constituent systems preserve the power to run independently, however their operational mode normally is subordinated to the purpose that are managed centrally [12]. The constituent systems intended to achieve specific purposes. Most likely these constituents owned by single organization.

Acknowledged SoS: have objectives, resources and nominated manager. the constituent systems of Acknowledged SoS maintain their objectives, development, sustainability, funding and autonomous ownership. The constituent systems of Acknowledged SoS work in collaboration to fulfill a larger target that cannot be achieved by themselves[13].

Collaborative SoS: consist of constituent systems that are independent, these systems cooperated voluntarily and there is no agreed director for these systems [14].

Virtual SoS: does not have central governance management authority. The participant systems in the virtual SoS may not agree on the objectives of the system. Virtual SoS depends on mechanisms that are invisible in order to preserve it [8].

\section{ili. Education System as Systems of SYSTEMS SOS}

Education system considered as one of the large-scale Systems of Systems SoS. Education system consists of constituent systems such as Ministry of Education, Universities, Colleges, Educational institutes, Schools, Students, Parents, Teachers, Transportation and Supporting Services i.e. maintenance, cleaning and security services. In this research paper, Author is concentrating on Online Distance Education System as Systems of Systems.

\section{Online Distance Education System as System of Systems SOS}

Technology development have affected educational delivery around the world. Online learning is rising at a staggering pace [15]. Online Distance learning has become an urgent need recently. The use of distance learning has appeared in the past ten years, the learning has been extended by the technology from classrooms in the schools into online learning. However, what the world is witnessing today has made online distance learning so important. As an example, when the problem of the epidemic that hit most of the world countries and affected millions of people emerged i.e. Virus Covid 19, this urgent situation derive an urgent need for social distancing, and because the health and safety of our children as well as the people is a top priority for governments, the decision to implement online distance learning has been taken in many countries of the world.

The Theory of e-learning comprises of three components. E-learning may be described through a theory-based paradigm that relates learning tools, instructional techniques and pedagogical models or constructs [16]. However, author in this research paper concentrating on Online Learning as Systems of Systems. Online Distance Learning system considered as one of the large-scale Systems of Systems. Based upon the E-Learning Systems' Theoretical Framework [16] in which the E-Learning System consists of three main systems i.e. People, Technologies and Services. People such as students, teachers, Ministry of Education, technology providers and content providers. Technologies include content, communication and collaboration. Services include pedagogical models and Instructional strategies [16]. Based upon this E-learning System's Theoretical Framework the Online Distance Learning System can be described as Systems of Systems that consists of the following constituent systems: (a) People and it includes: students, Ministry of Education, The authors of the curriculum, Teachers, School Admins and supervisors, (b) Technologies and it includes: content and the software and platforms that are used for the communication and collaboration in the online education, (c) Services and it includes: IT support, and Telecommunication companies. In this research, author aim to investigate the Online Distance Education System Key challenges, then author will propose the Future of Online Distance Education that can be considered as a solution for the current Online Distance Education implementations challenges. Figure 1 below illustrates the Online Distance Education System as SoSs. 


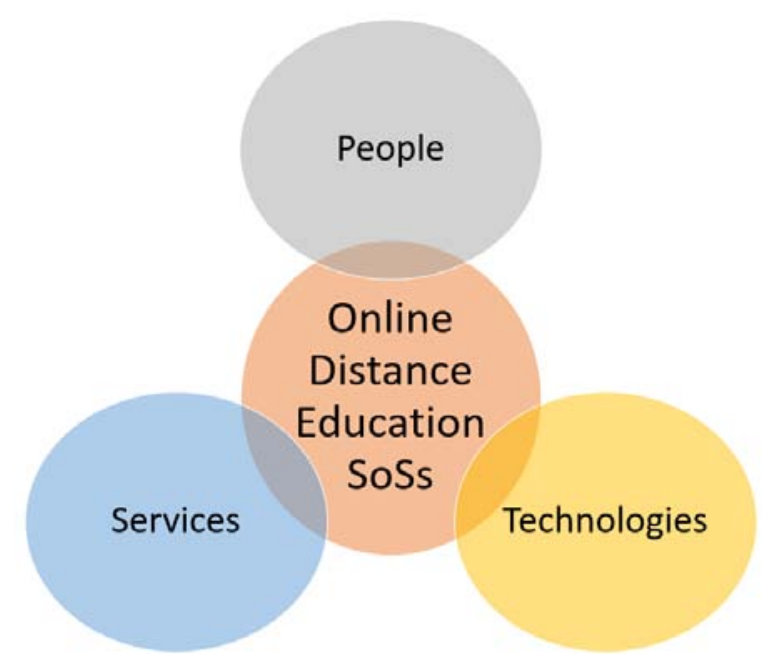

Figure 1: Online Distance Education SoSs.

\section{Online Distance Education System of Systems key Challenges}

The implementation of Online Distance Education System presented number of challenges. In this section, author explained the most common key challenges of the Online Distance Education System. The presented challenges are based upon the previously described constituent systems of Online Distance Education System:

\section{a) People}

\section{i. Achieve Learning Outcomes:}

The most recent works and researches that are centered on whether online learning is as successful as traditional learning in classrooms. For some studies online learning has been found to be equivalent to faceto-face learning in traditional classrooms in terms of the learning quality as well as the satisfaction of the students[15]. Additionally, the students received higher grades in the online learning followed by mix learning in which both online and traditional learning methods applied and then the traditional learning environments and this considered as indication that online learning is more successful than classroom-based learning [15]. However, the implementation of Online Distance Learning considered as challenging and may affect achieving the learning outcomes. For students it is hard for them to understand that the role of an instructor in an online classroom is much more student centered compared to traditional teacher-centered classrooms [17]. This may result in situations in which students fail to take on the role of an active learner and, as a consequence, they simply do not learn so well and this negatively affect achieving the learning outcomes[17].

\section{ii. Students Engagement}

Student Engagement in the Online Distance Learning is very important. Student Engagement is described as the student's psychological interest in, and effort to study, understand or master the information, skills or crafts that are intended to facilitate academic work [18].The student participation and engagement in online learning is essential because the student participation can be shown as proof of the significant effort needed by students for their cognitive growth and their desire to construct their own skills, contributing to a high level of student achievement [18]. Students view online courses differently than traditional courses. Negative expectations can result in unfavorable learning results like reduced motivation and endurance [15]. The student's engagement in the Online Distance Learning considered as challenge. Some students may be embarrassed to ask questions or express opinions through online classes which affect the interactions and overall learning outcomes of them [17]. Strategies, methods and tools must be developed in order to ensure students engagement in the learning [18].

\section{iii. Students Evaluation}

Students Evaluation may be considered as a challenge while the implementation of Online Distance Education as it has been proven that grades of students while implementing online learning are better that the grades while implementing traditional Face-to-Face learning. The students received higher grades in the online learning followed by mix learning in which both online and traditional learning methods applied and then the traditional learning environments [15]. This may indicate that students achieved the learning outcomes, however this may also indicate that students may got help during the exam time, or they may navigate the web to get answers for exams questions.

\section{iv. Users Satisfaction}

Ensuring user's satisfaction considered as a challenge while implementing online distance education system. Students Satisfactions affected by different factors. Student participation raises the level of student satisfaction, moreover it improves student motivation to learn, decreases sense of isolation, and the performance of the online learning will be improved [18].In the online learning environment, importance of aligning educational material and assessment metrics with learning results is crucial to positive learning outcomes and student's satisfaction [15]. It is important as well to achieve teacher's satisfaction in order to motivate them for better teaching process. School Admins, Parents, accreditation team's satisfaction is important as well.

\section{v. Curriculum Design}

Designing a Curriculum that lead to achieve learning outcomes and student's satisfaction considered as a challenge while implementing Online Distance Education System. Researchers investigated the curriculum design factors that lead to efficient online learning in terms of outcomes and satisfaction [15]. Results presented that the following factors positively 
affected online learningprocess such as the designing of adaptable content and designing the content that promote student's interaction[15].

\section{vi. Ensuring the quality of education}

It is essential to ensure the quality of the delivered education for students while implementing Online Distance Education System. As In traditional Learning environment, usually school admins and supervisors keep track of the education process at schools, it is necessary to keep track of the education process online as well.

\section{vii. Some job titles and duties end}

The complete turning into the implementation of the Online Distance Education System may lead to some employees losing their jobs. For example, when applying the distance learning system, jobs related to each of the following services considered as not necessary, such as guarding, security, cleaning services, building maintenance services, and transportation services to and from school, which may result in negative effects on society, such as high unemployment. On the other hand, this may have positive effects, such as the termination of transportation usage will positively affect the environment by reducing emissions and improve the air quality.

\section{b) Technologies}

There are number of challenges that are related to technologies while implementing Online Distance Education System.

\section{i. Availability of Devices}

In order to effectively implement the Online Distance Education System, it is essential to ensure that all students have their own device that they can use for learning. This can be considered as a challenge because some families with low income may not be able to offer each of their children a device that they can use for online learning. However, in many countries, charities sponsor education and provide electronic devices for needy students.

\section{ii. Achieving Security Requirements}

Online Distance Education System infrastructure represents a charming learning environment that's popularity increased, and people tend to increasingly interest in online courses[19]. However, Online Distance Education System infrastructure is fundamentally depending on the utilization of the Internet platform that witnessed an increasing set of illegitimate actions. The Online distance education System infrastructure may expose to different types of threats. [19]. Moreover, several online learning platforms are carried out without considering many of the security concerns [19]. It is highly recommended to address security requirements and fulfill them while implementing Online Distance Education System. iii. Ensuring Privacy of the users i.e. students, teachers

Ensuring the privacy of the Online Distance Education System's users is critical issue. Some of the implementation in this field include signing term of use policy and setting up a penalty list for any break of the privacy for the system's users.

\section{c) Services}

\section{i. Internet Connection Reliability}

Internet connection has great impact on the process of online learning process. A study conducted in order to examine the relationship between student's success and the bandwidth connectivity and it concluded that students that have higher bandwidth connectivity engaged more in the online classes and their grades are higher as well [20]. It is essential to ensure that the Internet connection is reliable, and its bandwidth is high while implementing Online Distance Education System for both students and instructors.

\section{The Research Agenda: the Future of Online Distance Education that can be Considered as a Solution for the Current Online Distance Education Implementations Challenges}

The author of this research paper aim to offer a research agenda that identifies 11 proposed frameworks and approaches to overcome the challenges of the implementation of Online Distance Education System. Figure 2 below represent the adopted strategies for Research themes generation[8]. Below are the research themes suggested to overcome the current Online Distance Education implementations challenges. Please Note that the research themes listed without any importance priority. Table1 represent brief description of each research theme.

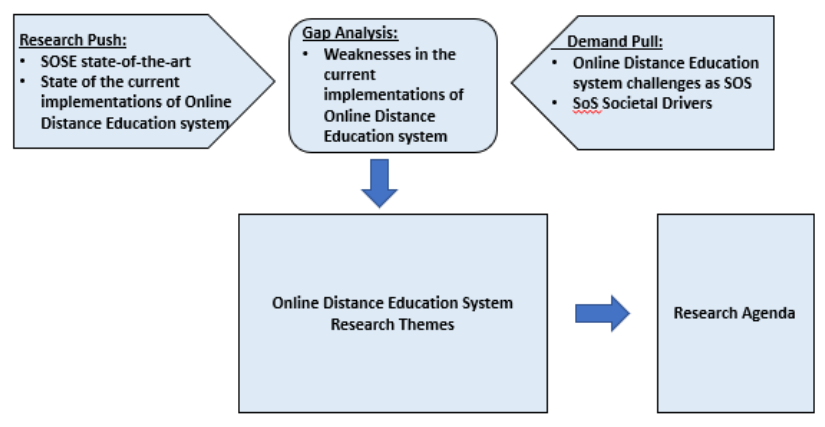

Figure 2: The adopted strategies for Research themes generation [8] 


\section{Below represented research themes in no priority order:}

Table 1: Brief description of each of the 11-research theme

\begin{tabular}{|c|c|}
\hline Research Theme & Brief Description \\
\hline $\begin{array}{l}\text { Achieve Learning } \\
\text { Outcomes }\end{array}$ & $\begin{array}{l}\text { This research theme addresses the research need to develop approaches to ensure } \\
\text { achieving learning outcomes while using complex SoSs that makes it hard to achieve the } \\
\text { requested learning outcomes. }\end{array}$ \\
\hline Students Engagement & $\begin{array}{l}\text { This research theme addresses the research need to develop approaches for ensuring } \\
\text { student's engagement while using complex SoSs that makes the students engagement hard } \\
\text { to measure. }\end{array}$ \\
\hline Students Evaluation & $\begin{array}{l}\text { This research theme addresses the research need to develop approaches and framework for } \\
\text { student's evaluation to ensure fair evaluation of students while using complex SoSs that } \\
\text { makes the fair evaluation of students hard to accomplish. }\end{array}$ \\
\hline Users Satisfaction & $\begin{array}{l}\text { This research theme addresses the research need to develop approaches for ensuring } \\
\text { user's satisfaction while using complex SoSs that makes the users satisfaction hard to } \\
\text { achieve. }\end{array}$ \\
\hline Curriculum Design & $\begin{array}{l}\text { This research theme addresses the research need to develop approaches and framework for } \\
\text { designing effective curriculum while using complex SoSs that makes it hard to design } \\
\text { effective and suitable curriculum. }\end{array}$ \\
\hline $\begin{array}{l}\text { Ensuring the quality of } \\
\text { education }\end{array}$ & $\begin{array}{l}\text { This research theme addresses the research need to develop approaches and framework for } \\
\text { ensuring the quality of the education while using complex SoSs that makes it hard to ensure } \\
\text { the quality of the learning and teaching process. }\end{array}$ \\
\hline $\begin{array}{l}\text { Some job titles and } \\
\text { duties end }\end{array}$ & $\begin{array}{l}\text { This research theme addresses the problem of increasing in unemployment percentage due } \\
\text { to the fact that the use of online education system may result in ending some job titles and } \\
\text { duties. This research theme addresses this challenge and how to overcome its effects. }\end{array}$ \\
\hline Availability of Devices & $\begin{array}{l}\text { This research theme addresses the need to ensure the availability of Devices for both } \\
\text { students and instructors that can be used for online learning while using complex SoSs. }\end{array}$ \\
\hline $\begin{array}{l}\text { Achieving Security } \\
\text { Requirements }\end{array}$ & $\begin{array}{l}\text { This research theme addresses the need to achieve security requirements that provide a } \\
\text { holistic security vision for ensuring the security of complex SoSs which are liable to constant } \\
\text { changes that makes them exposed to new threats }\end{array}$ \\
\hline $\begin{array}{l}\text { Ensuring Privacy of the } \\
\text { users i.e. students, } \\
\text { teachers }\end{array}$ & $\begin{array}{l}\text { This research theme addresses the need to ensure privacy of the users which provide a } \\
\text { holistic vision for the requirements to ensure users privacy while using complex SoSs which } \\
\text { are susceptible to constant changes that makes the users exposed to break into their } \\
\text { privacy. }\end{array}$ \\
\hline $\begin{array}{l}\text { Internet Connection } \\
\text { Reliability }\end{array}$ & $\begin{array}{l}\text { This research theme addresses the research need to ensure the reliability of the internet } \\
\text { connection while using complex SoSs that makes the unreliable internet connection may } \\
\text { result in systems' failure. }\end{array}$ \\
\hline
\end{tabular}

a) Theme 1: Online Distance Education System Approaches to ensure Achieving Learning Outcomes

Achieving learning outcomes is one of the most important goals of the educational system. When applying the online distance learning system, achieving learning outcomes is a real challenge. It is essential to ensure that this goal is achieved, however, it may be hard to measure while applying online learning system. The author of this research paper believes that it is essential to develop a framework to ensure achieving learning outcomes, the framework should consider the following points: First, All the learning outcomes must be clear and clarified in the beginning of each online session, before the end of each online session it is recommended to apply short quiz to evaluate the level of achieving learning outcomes, moreover, it is recommended as well to explore students opinions after each online session. Second, explore students that need extra lessons and explanations and offer them extra classes in order to ensure that the learning outcomes are achieved. Third, strategies and plans needed to be developed for the purpose of achieving learning outcomes while implementing the online distance learning system. Forth, it is recommended to develop smart application that capture students' understandings levels based upon their performance in all of the online subjects and predict students' performance as well. Finally, it is recommended to explore other successful implementations of online distance learning systems worldwide and benefit from their experience.

\section{b) Theme 2: Online Distance Education System Approaches to ensure Students Engagement}

The student's engagement has great impact on student's satisfaction, motivation and achieving learning outcomes. Students engagements in the online distance classes is an indication of the successful online distance education process. Moreover, it motivates student to learn and teachers to innovate. Author of this research paper believes that it is essential to develop framework for ensuring student's engagement in the education process while implementing online distance education 
system. The developed framework should consider the following recommendations: first, the developed curriculum must be attractive and encourage student's engagement. Second, part of the evaluation of student's performance must consider student's engagement in online classes. Third, strategies and plans must be developed to include several ways that ensure student's engagement. Forth, smart software can be used and installed in student's devices in order to monitor their behavior during online classes and detect student's engagement during the online classes as well. In the case of young students, specialists in children's behaviors and parents' opinions could provide valuable recommendations for ensuring students engagement during online classes.

c) Theme 3: Online Distance Education System Framework for effective students' evaluation

Researches and studies that dealt with the level of students performance when applying the online distance learning system have proven that students' grades were higher than when applying the traditional education system, this may be an evidence of the effectiveness of online distance learning system, but it may also be an indication of the lack of credibility of the evaluation when applying the online distance learning system, for example, the student may receive external assistance during the application of exams, or the student may use external sources or the web, for example, to answer questions. Hence, it is clear that effective evaluation of students when applying the distance learning system may constitute a real challenge. In this regard, number of suggestions and approaches have been proposed. The author of the research paper believes that evaluation framework must be set up and number of points should be considered. First, the students should be evaluated not only based upon exams, participation during the online class should be considered. Second, online exams should have protocols like keeping the cameras and microphones on. Third, exam questions must be reviewed against the web to make sure that students cannot find their answers there. Forth, it is advisable to develop software that is mandatory to be installed in students' devices which can be used for detecting students' behavior during online exams, further approaches can be considered as well. Moreover, teachers can participate in developing the online evaluation framework as well.

d) Theme 4: Online Distance Education System Approaches for ensuring user's satisfaction

One of the most important factors in the success of the educational SoS is the satisfaction of users, whether they are students, teachers, school administration and parents. When implementing online distance learning system, achieving user satisfaction is a real challenge. The satisfaction of the student and the teacher must primarily be achieved. In order to ensure user's satisfaction, it is essential to develop framework that consider the following points: First, ensure students participation in the online classes as the student participation raises the level of students satisfaction, improves student motivation to learn, and decreases sense of isolation, moreover it raises teacher's satisfaction as it indicated the effectiveness of learning. Second, it is essential to align educational materials with assessment metrics which lead to positive learning outcomes and student's satisfaction. Third, it is important to continuously support and appreciation for efforts of students as well as teachers. Forth, to investigate and survey user's point of view about all systems aspects in order to improve it and ensure users satisfactions. Fifth, strategies and plans needed to be developed in order to take necessary steps that will positively lead to user's satisfactions. Finally, exploring different successful implementations of online distance education system worldwide will help in developing a holistic vision about framework for achieving user's satisfactions.

\section{e) Theme 5: Online Distance Education System Framework for Curriculum Design}

Designing the appropriate curriculum for the online distance learning process is a real challenge for curriculum developers and teachers as well. An approach should be developed in which all required educational outcomes can be achieved while applying a distance learning system over the Internet. Therefore, the author of this research paper believes that a framework for curriculum design should be developed and consider the following points: It is advised to take advantage of other experiences in preparing curriculum for online learning, the prepared curriculum should be suitable with different age stages, moreover, the prepared curriculum for online learning should enforce students to engage in learning process, additionally, the developed curriculum should require students participation, moreover, teachers and students feedback about curriculum must be taken into consideration. Finally, the developed software and applications that are used for online learning such as virtual labs, and virtual classrooms should be improved in a way that makes the students feel as if they are in real classroom environment.

f) Theme 6: Online Distance Education System Approaches for ensuring the quality of education

It is very important to ensure the quality of education processes when applying the online distance learning system. In the traditional learning environment, many methods are used to ensure the quality of the education process, such as achieving learning outcomes, students results, accreditation teams, and school evaluation, and the largest role of school administrations that continuously visit classrooms and follow levels of academic achievement for the students. 
Thus, in the context of SOSE, an approach should be followed in order to ensure the quality of the education process while using online distance learning system. Number of points should be taken into consideration: first, Administration continuous to attending online sessions along with students. Second, Accreditation teams continuous to visit online schools and evaluate education process. Third, surveys and feedback should be requested from students as well as their parents in the case of young students. Forth: sudden online quizzes should be held in continuous manner, fifth: all the online sessions must be recorded and saved for later usage. Finally, strategies of ensuring online education quality must be developed in which all of the users of Online Distance Education SoSs must be involved such as: managers, teachers, students, members of Education Ministry, members of accreditation teams, curriculum developers as well as parents.

g) Theme 7: Online Distance Education System Framework for minimizing the effects of unemployment

The implementation of the online distance learning SoS has many benefits to society, individuals and the environment. For example, applying an online distance learning system contributes to reduce the expenses from financial budget of schools such as guarding, cleaning and maintenance services and the costs of school services such as electricity, water and communications services, also it has a great benefit to the environment as the implementation of the online distance learning system means dispensing with school transportation Which directly affects improving air quality by reducing emissions from school buses and cars that transport students to and from schools. Also, the implementation of online distance learning system enhances the student's confidence by transforming the dependence on the teacher in learning in the traditional education environment into the dependence on the student, whereby the student conducts researches and explorations and attempts to solve problems, which also enhances the research skills of students. On the other side, some job titles and duties will be end, like for example school guard, school cleaners, bus drivers, which will result in raising the percentage of unemployment in the community. The author of this research paper believes that it is necessary to cooperate with government agencies for human resources to find a solution to this problem and limit its negative effects on families and individuals in society. Plans and strategies must be developed to ensure that individuals who have lost their jobs are transferred to other institutions that are in need of employees, moreover, It is recommended to cooperate with charities to provide the necessary financial supports for them during this period until they can obtain other jobs.

\section{h) Theme 8: Availability of Devices Requirements for} Online Distance Education SoSs

One of the biggest challenges facing the success of the implementation of online distance education system is ensuring that there is an electronic device for each student. Some families with low incomes may not be able to offer an electronic devices for their children, or they may provide an electronic device which more than one of their children share it, which may affect the effectiveness of learning, as it is possible that two of their children have an online class at the same time. Hence, the author of this research paper highly recommend that it is essential to collaborate all the efforts between the government, Education Ministry and the charities in the country to ensure that there is an electronic device for every student studying in the online distance learning system. Thus, in the context of SOSE, a framework must be developed in order to ensure the availability of devices for each student. First, the student's family's financial situations must be surveyed in order to investigate and report the families with low income. Second, a survey sent to the low-income families to explore whether they have devices for each of their children. Third, plan must be developed to offer devices to the students that are in need based upon agreement between Education Ministry and Charities in the country. Forth, ensure that families with low income have internet connection at their houses. Fifth, continuous check and investigate to ensure the availability of devices for each student studying in the online distance education system.

\section{i) Theme 9: Security Requirements for Online Distance} Education SoSs

Although the interaction between the constituent systems of the Online Distance Education SoSs offer huge benefits, this interaction may result in different forms of security breaches. Therefore, it is essential to ensure the security confidence between the constituent systems of the Online Distance Education SoSs. Thus, in the context of SOSE, it is essential to ensure that each of the constituent systems of the Online Distance Education SoSs are secure. However, many factors may affect the process of ensuring the security of the constituent systems of the Online Distance Education SoSs such as the graphical distribution, and SoSs are independently operated and managed. For this challenge, author of this research paper believes that the utilization of Blockchain-Based Security Requirements Engineering Framework [8]for ensuring the security of the constituent systems of the Online Distance Education SoSs. The blockchain is growing as one of cyber security's most propitious and cleverest innovations [21]. Using Blockchain to ensure the security of SOSs for Online Distance Education System would merge a consensus mechanism in the architecture of the SoSs that would allow a majority or all 
constituent systems to agree to work as a group or even survive if some of them were compromised [8]. The author of this research paper believes that a Blockchainbased Security Requirements Engineering Framework would provide great protection for overall SoSs of the Online Distance Education System. It would be great if strategies that ensure the security of the constituent SoSs of the Online Distance Education System developed. Moreover, Agreement of the security rules must be signed up by all of the users in the constituent systems of the Online Distance Education SoSs.

\section{j) Theme 10: User's Privacy Requirements for Online Distance Education SoSs \\ Although the utilization of Online Distance}

Education SoSs offer huge benefits, this utilization may result in privacy breaks for the systems users. Therefore, it is essential to ensure the privacy of the users of the constituent systems of the Online Distance Education SoSs. Thus, in the context of SOSE, it is essential to ensure that the privacy of each of the users of each of the constituent systems of the Online Distance Education SoSsis achieved. However, many factors may affect the process of ensuring the privacy of the users of the Online Distance Education SoSs such as the systems independencies and the graphical distribution. For this challenge, author of this research paper believes that a trust-based framework which facilitates the automated integration of trust-based policies is important [22]. Moreover, access control services should be sufficiently flexible to capture the dynamic, context, or attributes or credential-based access requirements and enforce the least privilege principle [22]. These access management systems can need to include standards for privacy security, articulated by specific laws [22]. Privacy policy must be set and consider all concepts related to the privacy of each user in the system.

The author of this research paper believe that a Blockchain-based Security Requirements Engineering Framework would enhance privacy protection for all SoSs users of the Online Distance Education System. It would be great to develop strategies that ensure the privacy of the constituent SoSs of the Online Distance Education System users.

k) Theme 11: Internet Connection Reliability Requirements for Online Distance Education SoSs

One of the important requirements while implementing an online distance education system is to ensure Internet Connection Reliability. Actually, any unreliable or poor connection will strongly have negative effects especially for the live online classes. Thus, in the context of SOSE, it is essential to ensure the reliability of the internet connection during the implementation of online distance education system. First, ensure that all students have a strong internet connection at their home. Second, the Education Ministry should sign a contract with the Internet Service Providers companies by which they offer the internet connection with strong connectivity and high bandwidth to students. Third, it is recommended to sign an agreement with Internet Service Providers companies by which the internet connection offered free of charge while using any platform or website for the education purposes. Forth, all online sessions must be recorded and offered for students by which student who has failed to connect to the live online session can attend the recorded class. Fifth, an emergency technical teams must be available for technical assistant on daily manner, especially during the online classes.

\section{Vil. Timelines and the Need for A New Research Agenda}

Author believes that great efforts have been accomplished in addressing some of the mentioned challenges, however, author believes that the proposed research themes in this research paper may help to cope with the challenges of Online Distance Education SoSs.

Author of this research paper believes that the research agenda that is proposed in this research paper offer a road map for the coming 25 years. Author believes that all community parts should actively involve in the proposed research themes to overcome the challenges while implementing Online Distance Education System. The proposed research themes in this research paper can be considered as a foundation for the methods, approaches, tools and techniques of SoSE. Governments and Educational Institutes should invest in the online learning field in order to reach powerful future of online distance learning.

\section{Vili. Conclusion}

The emergence of the internet has great effects in peoples' lives. Recently, statistics presented that peoples tend to use internet in an increasing manner, and this affected the development in the field of Technology and motivated it. Online learning has become an urgent need recently. Online Learning adopted in various educational institutions worldwide. Although the online learning has been implemented years ago, still it faces challenges. The author of this research paper presented the key challenges that reported while implementing Online Distance Education System as Systems of Systems. The author then outlines research agenda that identifies 11 research themes that can be considered as a solution for the current Online Distance Education System implementations challenges.

\section{Acknowledgements}

This work is a part of a project undertaken at the British University in Dubai. 


\section{References Références Referencias}

1. I. Y. Kazu and M. Demirkol, "Kazu, I. Y., \& Demirkol, M. (2014). Effect of Blended Learning Environment Model on High School Students' Academic Achievement. Turkish Online Journal of Educational Technology - TOJET, 13(1), 78-87. Retrieved from http://search.ebscohost.com/login.aspx?d," Turkish Online J. Educ. Technol. - TOJET, vol. 13, no. 1, pp. 78-87, 2014.

2. T. Nguyen, "The Effectiveness of Online Learning: Beyond No Significant Difference and Future Horizons," MERLOT J. Online Learn. Teach., vol. 11, no. 2, pp. 309-319, 2015.

3. R. Croxton, "The role of interactivity in student satisfaction and persistence in online learning," J. Online Learn. Teach., vol. 10, no. 2, p. 314, 2014.

4. Dahmann, Judith \& Rebovich, G. \& Lowry, Ralph \& Baldwin, Kristen. (2011). An Implementers' View of Systems Engineering for Systems of Systems. Aerospace and Electronic Systems Magazine, IEEE. 27. 10.1109/SYSCON.2011.5929039.

5. D. Firesmith, "Profiling Systems Using the Defining Characteristics of Systems of Systems (SoS)," no. February, pp. 1-74, 2010.

6. Horizon 2020, The EU Framework Programme for Research and Innovation. [Online]. Available: http://ec.europa.eu/programmes/horizon2020/. [Accessed: 21 January 2018].

7. Tariq Samad and Thomas Parisini, "Systems of Systems," Syst. Syst., 2013, from The Impact of Control Technology, T. Samad and A.M. Annaswamy (eds.), 2011. Available at www.ieeecss. org by DOYLE, Frank, IEEE control systems. 2011, Vol 31, Num 5, pp 26-27, 2 p ISSN 1066-033X

8. C. Ncube and S. L. Lim, "On systems of systems engineering: A requirements engineering perspective and research agenda," Proc. - 2018 IEEE 26th Int. Requir. Eng. Conf. RE 2018, pp. 112123, 2018.

9. C. B. Keating and P. F. Katina, "Systems of systems Engineering: Prospects and challenges for the emerging Systems of systems engineering: prospects and challenges for the emerging field," no. June 2011, 2015.

10. J. Ring and A. M. Madni, "Key challenges and opportunities in 'system of systems' engineering," 2005 IEEE International Conference on Systems, Man and Cybernetics, Waikoloa, HI, 2005, pp. 973978 Vol. 1.

11. Dahmann, J. Systems of Systems: A Systems Engineering Perspective. In Complex System Design \& Management Conference. Paris: Springer Berlin Heidelberg. 2013.

12. I. Khlif, A. H. Kacem, and K. Drira, "A multi-scale modelling perspective for SoS architectures." ECSAW 14: Proceedings of the 2014 European
Conference on Software Architecture Workshops. August 2014 Article No.: 30 Pages 1-5 from https://doi.org/10.1145/2642803.2642833.

13. S. Agarwal, R. Wang, and C. H. Dagli, "Executable architectures using cuckoo search optimization coupled with OPM and CPN-A module: A new metaarchitecture model for FILA SoS," Complex Syst. Des. Manag. - Proc. 5th Int. Conf. Complex Syst. Des. Manag. CSD M 2014, pp. 175-192, 2015.

14. C. Ingram, R. Payne, J. Fitzgerald, and L. D. Couto, "Model-based Engineering of Emergence in a Collaborative SoS: Exploiting SysML \& Formalism", Wiley Online Library. October 2015. From https:// onlinelibrary.wiley.com/doi/abs/10.1002/j.23345837.2015.00071.x.

15. H. Kauffman, "A review of predictive factors of student success in and satisfaction with online learning," Res. Learn. Technol., vol. 23, no. 1063519, pp. 1-13, 2015.

16. M. Aparicio, F. Bacao, T. Oliveira, I. Universitario, D. L. I. I. Nova, and U. N. De Lisboa, "An e-Learning Theoretical Framework," vol. 19, pp. 292-307, 2016.

17. R. Damary, T. Markova, and N. Pryadilina, "Key Challenges of On-line Education in Multi-cultural Context," Procedia - Soc. Behav. Sci., vol. 237, no. June 2016, pp. 83-89, 2017.

18. F. Martin and D. U. Bolliger, "Engagement Matters: Student Perceptions on the Importance of Engagement Strategies in the Online Learning Environment," vol. 22, no. 1, pp. 205-222.

19. Y. Khlifi and M. M. Allehaibi, "Information Security Services and Requirements for E-learning Infrastructure Success." 2014 World Congress on ELearning, Education and Computer Science (WCEECS'2014), Hammamet.

20. B. J. Dray, P. R. Lowenthal, M. J. Miszkiewicz, M. A. Ruiz-Primo, and K. Marczynski, "Developing an instrument to assess student readiness for online learning: A validation study," Distance Educ., vol. 32, no. 1, pp. 29-47, 2011.

21. D. Puthal, N. Malik, S. P. Mohanty, E. Kougianos and C. Yang, "The Blockchain as a Decentralized Security Framework [Future Directions]," in IEEE Consumer Electronics Magazine, vol. 7, no. 2, pp. 18-21, March 2018, doi: 10.1109/MCE. 2017. 2776459.

22. H. Takabi, J. B. D. Joshi and G. Ahn, "Security and Privacy Challenges in Cloud Computing Environments," in IEEE Security \& Privacy, vol. 8, no. 6, pp. 24-31, Nov.-Dec. 2010, doi: 10.1109/MSP. 2010.186 . 